\title{
Modeling Acceptance of Electric Vehicle Sharing Based on Theory of Planned Behavior
}

\author{
Kai Zhang ${ }^{1}$, Hongwei Guo ${ }^{2, *}$, Guangzheng Yao ${ }^{3}$, Chenggang $\mathrm{Li}^{2}{ }^{\circledR}$, Yujie Zhang ${ }^{2}$ and \\ Wuhong Wang ${ }^{2, *}$ \\ 1 School of Law and Economic, China University of Political Science and Law, Beijing 100088, China; \\ cigar_china@163.com \\ 2 School of Mechanical Engineering, Beijing Institute of Technology, Beijing 100081, China; \\ elane100@163.com (C.L.); zhangyujiebit@126.com (Y.Z.) \\ 3 College of Metropolitan Transportation, Beijing University of Technology, Beijing 100124, China; \\ yaogz@shou.com (G.Y.) \\ * Correspondence: guohongwei@bit.edu.cn (H.G.); wangwuhong@bit.edu.cn (W.W.)
}

Received: 15 October 2018; Accepted: 21 November 2018; Published: 10 December 2018

\begin{abstract}
The electric vehicle (EV) is a kind of innovation helping to address the issue of climate change and conventional energy consumption, compared to internal combustion engine vehicles. Electric vehicle sharing is a new way to promote the market penetration of electric vehicles due to its convenience and economy. Aiming to provide a more profound understanding of the influential factors in the acceptance of electric vehicle sharing, a structural equation model is proposed based on the theory of planned behavior as the policy environment has been added as prepositive variable. The data about the travelers' perspective of electric vehicle sharing are acquired from questionnaires in Beijing. The results indicate that the perceived behavioral control is the primary factor with positive contributions to EV-sharing acceptance. Subjective norm, ranking second, is also proven to exert a significant positive effect on EV-sharing acceptance. The results also reveal the insignificant relationship between the attitude towards behavior and sharing acceptance, which is consistent with relevant research. Moreover, the significant positive effects of policy support on attitude and subjective norm are demonstrated. Finally, strategies to promote electric vehicle sharing are proposed, including providing more accessible resources (charging facility, service station), improving social pressure (free trial, sharing atmosphere), and strengthening policy support (financial support, legal guarantee). This study can give a better understanding of the acceptance of EV sharing and the strategy to promoting EV sharing in urban traffic.
\end{abstract}

Keywords: theory of planned behavior; electric vehicle; acceptance of sharing; structural equation model

\section{Introduction}

The electric vehicle (EV) has the potential for reducing greenhouse gases (GHGs) and tailpipe emissions that public road users are exposed to if its sources come from low-carbon electricity. In consideration of its benefits, the use of EVs has been promoted on a large scale from the last decade. Many countries enacted regulations to promote the market penetration of EVs, such as American Clean Energy and Security Act in 2009, Germanic National Electromobility Development Plan in 2011, and Japanese Next-Generation Plan in 2011 and Chinese Energy Saving and New Energy Vehicle Industry Planning in 2012.

Meanwhile, car sharing with EVs as a new emerged travel mode provides travelers a flexible alternative that not only meets diverse transportation needs, but also reduces the environmental 
negative impacts due to its zero emissions and reproducible energy source features. The existing studies have discussed the incentives and hindrances related to car-sharing acceptance targeted at conventional internal combustion engine vehicles (ICEVs). Those studies typically employ stated preference questionnaires to analyze demographic statistics. Baum and Pesch [1] concluded that money saving was not the primary cause for German consumers to attend car-sharing clubs, while short distances between residential areas and sharing stations and sufficient shared vehicles ranked as the top two prerequisites. After examining the samples from Portland, Katzev [2] argued that money saving and demand for other types of automobiles were the principle purposes of participating in car sharing. As for the obstacles for widespread car sharing, Lightfoot [3] attributed the immature service quality, such as the higher charging fares, insufficient vehicle types, and long receiving distance to some Europeans' unwillingness to participate in car sharing. Through a comparison of car-sharing operations among international countries, including similarities and differences, Shaheen et al. [4] identified three main factors, namely, cost savings, convenient locations, and guaranteed parking, as the most common motivations for ICEV sharing. It can be said that the development of car sharing is affected by the Sustainable concept [5].

As car sharing presents advantages in economy and convenience, some researchers have proposed the mutual development of car sharing and EVs $[6,7]$. Given that car-sharing organizations appeal to environmentalists and innovators [8], the marriage of EV and car sharing attracts more participants due to EVs' environmental and cutting-edge technologies. Moreover, as most people get used to driving conventional ICEVs, participating in EV sharing might shape a new perspective about EVs and strengthen the desire for owning a private one. Indeed, EV-sharing programs have already been in operation in many countries and areas, including profit-driven programs such as Autolib in Paris and Bemobility in Berlin, and experimental items like Intellishare in America [9,10]. Kim [11] conducted a questionnaire-based survey to investigate EV-sharing program participants and found their social and economic perspectives significantly affect the attitude. The study focused on participants' socioeconomic characteristics instead of external factors like policy support, subjective norm, and so forth. A comprehensive study on both consumers' characteristics and external factors is required [12].

Moreover, EV sharing is still at the primary stage in developing countries like China, while public travelers unwillingly accept it due to a lack of experience. Today, Beijing (capital of China) is operating three EV-sharing programs with similar pricings and operational rules. Travelers have a strong willingness to join the EV program as a result of the demanding car purchasing rules and use regulations in Beijing [13].

In order to better push forward EV sharing in Chinese cities, finding positive and negative factors as well as constructing their influential mechanism play a fundamental role in the research of consumers' acceptance. Through the previous findings in ICEV sharing and EV purchasing, driving range, charging time, and financial incentives are the main considerations for using or purchasing electric vehicles. But the main obstacles and motivations are still unknown for EV sharing, particularly for a new emerging market. So far, it is incapable of revealing the quantitative relationship between contributors and consumers' acceptance. To establish a more mature framework of the influential mechanism of EV-sharing acceptance, this paper is one of the first combining the features of carsharing and EV adoption to construct a structural equation modeling (SEM) based on theory of planned behavior (TPB). SEM is proven to be a useful tool to understand the nature of the relationships among consumers' diverse motivations: instrumental, symbolic, and affective [14]. The TPB is applied to assist survey design that links individual beliefs and behavior [15]. The developed method by combining SEM and TPB for investigating EV-sharing acceptance is innovative and can be adopted in a wide range of case studies.

The data about drivers' attitudes towards and preference for EV sharing are collected from questionnaires in Beijing. With the estimated model, drivers' attitudes towards EV sharing and the factors on the acceptance of EV sharing are analyzed quantitatively. The results are hoped to give a better understanding of the acceptance of EV sharing and promote EV sharing in urban traffic. 
The main contribution of the study is to address the key considerations of consumers in order to effectively operate and expand EV-sharing programs. Particularly, the factor of policy support is for the first time included in the TPB to analyze the acceptance of EV sharing. Its results also intend to provide policy makers with some implications about the issues using a questionnaire-based survey. The remaining part of the paper is organized as follows. First, the feasibility of the application of TPB is confirmed and the questionnaire is designed accordingly. Then, the reliability and the validity tests are carried out with the collected data samples from Beijing. Next, the acceptance mechanism of EV sharing is revealed through the justified SEM. Finally, relevant suggestions are proposed to promote EV sharing.

\section{Methodology}

\subsection{Theory of Planned Behavior}

The theory of planned behavior can be applied to assist in the understanding of residents' EV-sharing acceptance owing to the fact that EV sharing is purchasing behavior. A purchasing behavior is under the influence of multitudinous factors, such as customer value, service quality, and customer participation [16]. Deriving from the theory of reasoned action [17], the theory of planned behavior (TPB) is a well-validated model to interpret social behaviors [18-20]. The theory of planned behavior maintains that intention is the most proximate determinant of behavior, characterizing the willingness that a person wants to perform a behavior. The intention is under the influence of three components, including the attitude towards the behavior, subjective norm, and perceived behavioral control [21]. Attitude towards the behavior characterizes how positively the behavioral consequences are predicted. Subjective norm characterizes the influential effects of social pressure to perform or not perform a behavior. Perceived behavioral control (PBC) characterizes how easy it is to perform an action in a person's perception. Relevant experiences and positive anticipation of difficulties help to increase the perceived behavioral control. In general, having more favorable attitudes towards behavioral consequence, greater pressures from important others, and greater behavioral control will result in the strong intention to perform the behavior [18].

It is important to note that a meta-analysis of 185 tests of the TPB provides support for the efficiency of the model, explaining $39 \%$ of the variance on average in intent, and $27 \%$ in behavior with a further $2 \%$ attributable to the perceived behavioral control across a variety of contexts. A further advantage of the TPB is the potential for the expansion of the standard construct with additional context-relevant factors with the premise that these factors explain additional variance [22]. Therefore, this paper employs an extended TPB construct to analyze the acceptance of EV sharing.

\subsection{Model Construction and Hypothesis}

According to the TPB, travelers' acceptance of EV sharing could be affected by three dependent variables: attitude towards the behavior, subjective norm, and perceived behavioral control (PBC). Besides that, it is necessary to introduce policy support as the fourth dependent variable to characterize the effect of policy instruments on the acceptance of EV sharing. As a new-emerging travel mode, EV sharing is also susceptible to government's policies. For instance, local road restrictions and traffic control for normal ICEVs are not applied to EVs, which might directly stimulate travelers to participate in EV sharing, especially for those who may not be able to own a car due to the car registration lottery. The car registration lottery is a typical traffic demand management measure to restrict the fast-growing number of vehicles in some Chinese cities, such as Beijing, Tianjin, and Shenzhen. Additionally, environmental protection regulations might lead people to participate in EV sharing such as launching stringent emission standards to make petrol vehicle users pay extra environmental tax, which might guide consumers to purchase zero mission EVs or participate in EV sharing. Based on the possible direct and indirect effects, government policy is another important factor which might influence the acceptance of EV sharing. 
With the combination of conventional TPB model and the added policy support variable, the model framework of travelers' acceptance of EV sharing is shown in Figure 1.

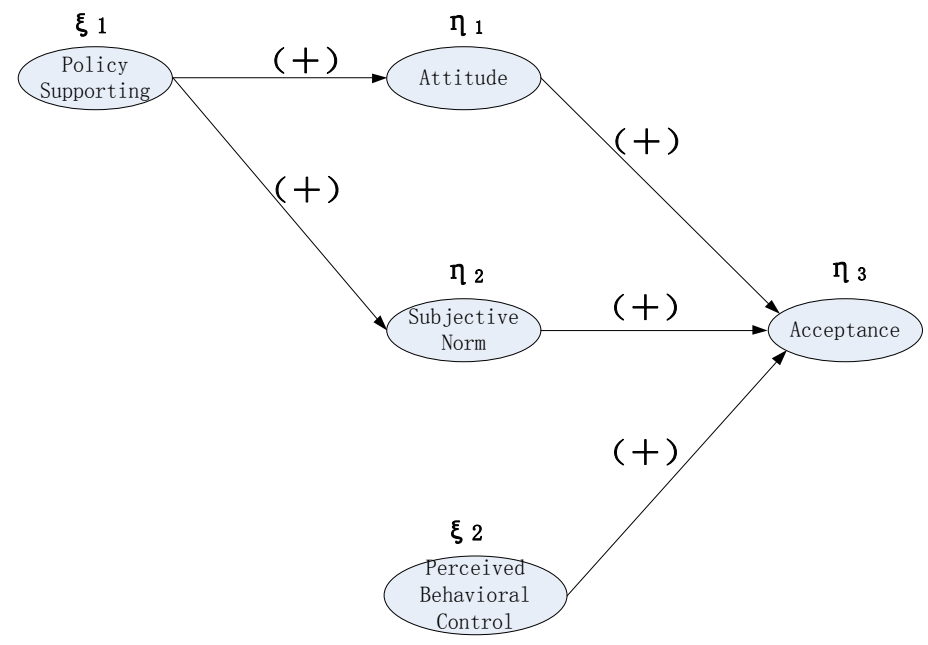

Figure 1. Theoretical model of consumers' acceptance of EV sharing.

As policy support $\left(\xi_{1}\right)$ could enhance consumers' positive experience in participating in EV sharing, we hypothesize policy support positively affects consumers' attitude $\left(\eta_{1}\right)$ towards sharing behavior. EV-supporting policies might also attract more travelers to enter EV sharing at the beginning stage. Experienced consumers may introduce such a new travel mode to their family members or friends according to their experience, in which the social pressure is formed. Thus, we hypothesize policy support positively affects subjective norm $\left(\eta_{2}\right)$. Although the relevant experience or positive anticipations of difficulties help to increase $\mathrm{PBC}\left(\xi_{3}\right)$, it is assumed to be determined by the total set of accessible control beliefs [23]. It is hard to change an individual's control beliefs although such EV-supporting policies provided for EV sharing. The control belief is defined as an individual's beliefs about the presence of factors that may facilitate or impede performance of the behavior [24]. Hence, we hypothesize there is no link path between policy support and perceiving behavioral control. Besides, Ajzen [24] argued that the more favorable the attitude toward behavior and subjective norm, the greater the perceived behavioral control, and the stronger the person's intention to perform the behavior. Based on the Ajzen's perspective, we hypothesize attitude $\left(\eta_{1}\right)$, subjective norm $\left(\eta_{2}\right)$, and perceived behavioral control $\left(\xi_{3}\right)$ all positively contribute to improve the acceptance of EV sharing $\left(\eta_{3}\right)$.

More specifically, we put forward 5 hypotheses as follows:

1. Attitude towards the behavior has a significant positive effect $(+)$ on the acceptance of EV sharing.

2. Subjective norm has a significant positive effect $(+)$ on the acceptance of EV sharing.

3. Perceived behavioral control has a significant positive effect $(+)$ on the acceptance of EV sharing.

4. Policy support has a significant positive effect $(+)$ on the attitude towards the behavior.

5. Policy support has a significant positive effect $(+)$ on the subjective norm.

\subsection{Structural Equation Modeling of EV Sharing Acceptance}

The Structural Equation Model (SEM) includes a measured model and a structural model. The measured model, shown as Equation (1) in the form of a matrix equation, is a linear function of a set of observed variables. It describes the relationships of latent variables and their corresponding observed variables. The structural model, shown as Equation (2) in the form of a matrix equation, describes the causal relationships among the latent variables.

$$
\gamma=\Lambda \eta+\varepsilon
$$


where $Y$ is the observed variable; $\Lambda$ is the factor loading of observed variable; $\eta$ is the latent variable; $\varepsilon$ is measurement error; $\eta$ has no relevance to $\varepsilon$.

$$
\eta=B \eta+\Gamma \xi+\zeta
$$

where $\eta$ is the endogenous latent variable; $B$ is the coefficient matrix among endogenous latent variables; $\xi$ is the exogenous latent variable; $\Gamma$ is the coefficient matrix among exogenous latent variables and endogenous latent variables; $\zeta$ is the residuals term; $\xi$ has no relevance to $\zeta$.

Based on the definition and the five hypotheses, the SEM of travelers' acceptance of EV sharing can be written in the form of a matrix equation as Equation (3).

$$
\left(\begin{array}{l}
\eta_{1} \\
\eta_{2} \\
\eta_{3}
\end{array}\right)=\left[\begin{array}{ccc}
0 & 0 & 0 \\
0 & 0 & 0 \\
\beta_{31} & \beta_{32} & 0
\end{array}\right]\left[\begin{array}{l}
\eta_{1} \\
\eta_{2} \\
\eta_{3}
\end{array}\right]+\left[\begin{array}{cc}
\gamma_{11} & 0 \\
\gamma_{21} & 0 \\
0 & \gamma_{32}
\end{array}\right]\left[\begin{array}{l}
\xi_{1} \\
\xi_{2}
\end{array}\right]+\left[\begin{array}{l}
\zeta_{1} \\
\zeta_{2} \\
\zeta_{3}
\end{array}\right]
$$

\section{Scale Development and Data Validation}

\subsection{Scale Development}

The main purpose of the TPB-based survey is to characterize the relationships between influential factors and the acceptance of EV sharing. Note that specific factors which have potential influence on EV sharing, such as limited range of EV and limited accessibility to charging facilities, are only observation items belonging to certain latent variables. Hence, not all specific factors are adapted as observation items in TPB-based questionnaires. The observation items of standard TPB variables are developed by taking reference of the testified scales while items of extended variables are developed by the authors. In general, the testified scale is divided into three sections according to their different purposes. The first section asks for the basic information of participants, including gender, age, daily travel mode, and the number of household vehicles, and so on. The second section examines the relevant knowledge of EV sharing, such as EVs' performance characteristics, economic benefits, environmental benefits, and government's incentive measures. Respondents' acceptance of EV sharing is evaluated in the third section with five subscales. Within this section, respondents rated their opinions by a five-point Likert scale, ranging from 1 (referring to strongly disagree) to 5 (referring to strongly agree). The specific items in the third section are shown in Table 1.

\begin{tabular}{|c|c|c|c|}
\hline Latent Variable & Item Number & Observation Item & Reference \\
\hline $\begin{array}{l}\text { The Attitude towards } \\
\text { Behavior } \\
\text { (AB) }\end{array}$ & 4 & $\begin{array}{l}\text { 1. EV sharing can satisfy my travel demand by automobile } \\
\text { if I can't afford a private one. } \\
2 \text {. EV sharing can meet my need of temporary automobile } \\
\text { usage. } \\
\text { 3. EV sharing contributes to environmental conservation. } \\
\text { 4. EV sharing provides an available automobile usage } \\
\text { method under the policy of vehicle registration via lottery } \\
\text { system and the vehicle usage restriction according to the } \\
\text { license plate. }\end{array}$ & {$[14,15]$} \\
\hline $\begin{array}{c}\text { Subjective Norm } \\
(\mathrm{SN})\end{array}$ & 3 & $\begin{array}{l}\text { 1. Family members and friends support my participation } \\
\text { in EV sharing. } \\
\text { 2. Family members and friends encourage me to } \\
\text { participate in EV sharing. } \\
\text { 3. Family members and friends expect me to choose EV } \\
\text { sharing to meet part of my travel demand. }\end{array}$ & {$[14,15]$} \\
\hline $\begin{array}{l}\text { Perceived Behavioral } \\
\text { Control } \\
\text { (PBC) }\end{array}$ & 2 & $\begin{array}{l}\text { 1. I am confident that I could attend EV sharing. } \\
\text { 2. If I want to, it would be easy for me to attend EV } \\
\text { sharing. }\end{array}$ & {$[14,15]$} \\
\hline
\end{tabular}

Table 1. Items in the five subscales of EV-sharing acceptance. 
Table 1. Cont.

\begin{tabular}{|c|c|c|c|}
\hline Latent Variable & Item Number & Observation Item & Reference \\
\hline $\begin{array}{l}\text { Sharing Intention } \\
\text { (SI) }\end{array}$ & 3 & $\begin{array}{l}\text { 1. After the survey, I will try to participate in EV sharing. } \\
\text { 2. After the survey, I will encourage my friends to } \\
\text { participate in EV sharing } \\
\text { 3. I plan to adopt EV sharing as an available travel mode } \\
\text { in the future. }\end{array}$ & {$[14,15]$} \\
\hline $\begin{array}{l}\text { Policy Support } \\
\text { (PS) }\end{array}$ & 2 & $\begin{array}{l}\text { 1. Government's vehicle restriction policies, such as } \\
\text { vehicle registration via lottery system and traffic } \\
\text { restriction according to license number, lead me to } \\
\text { participate in EV sharing. * } \\
\text { 2. Government's stringent emission regulations lead me to } \\
\text { choose "zero emission" EV sharing. }\end{array}$ & Authors designed \\
\hline
\end{tabular}

\subsection{Sample Distribution}

Samples were collected via a random sampling survey administered in the vicinity of the Beijing Institute of Technology charging station and the Tsinghua Science Park charging station, both located in Haidian District, Beijing. Before distributing the questionnaire, the study purpose and clear definition of questions were explained to each interviewee. The whole survey was finished in the form of street intercept. Given the goal of the study, the interviewee should have a driver's license and half a year's driving experience at least. Besides, interviewees' age was also a controlled factor for an eligible driver. Respondents aging from 18 to 55 were selected. Considering the preset requirements on age and driving license, and invalid questionnaires (not completed), this paper finally acquired 124 valid samples for the analysis. The mean of respondents' age was $31.6,45.3 \%$ of whom were female respondents. Moreover, $22 \%$ of the respondents chose walking and riding bicycles as their daily travel mode. The proportions of traveling by public transport and private vehicles were $44 \%$ and $20 \%$, respectively, and $14 \%$ of the interviewees were multimodal travelers, who usually used both public transport and private cars. Surprisingly, the car ownership ratio was $63 \%$ while $12 \%$ of the respondents had more than one car.

\subsection{Data Validation}

In this part, the proposed model will be verified and validated. The testified scale would be further used in model estimation. Item analysis is adopted to validate the effectiveness of each observation item. Unjustified items should modify the expression or be excluded from the scale to guarantee the persuasiveness of the conclusion. The method of item-scale correlations is adopted to process the item analysis among 14 items (in Table 1). The outcome shows that $t$ values of all items are less than 0.05 , which verify the effectiveness of each item.

The principal component analysis (PCA) is used to testify the convergent validity. Using the varimax orthogonal rotation ( $\mathrm{KMO}=0.647>0.6, \mathrm{KMO}$ means Kaiser-Meyer-Olkin), the component matrix is shown in Table 2 and the coefficients more than 0.6 are emphasized by boldface. As the items merely fall a small weight (all less than 0.4 ) on the principle components they don't belong to, it leads to the conclusion that the scale has a good convergent validity. 
Table 2. The component matrix of items in proposed model.

\begin{tabular}{cccccc}
\hline Observed Variable & \multicolumn{5}{c}{ Component } \\
\cline { 2 - 6 } & $\mathbf{1}$ & $\mathbf{2}$ & $\mathbf{3}$ & $\mathbf{4}$ & $\mathbf{5}$ \\
\hline SI1 & 0.262 & $\mathbf{0 . 8 3 9}$ & 0.044 & 0.245 & 0.191 \\
SI2 & 0.028 & $\mathbf{0 . 7 7 0}$ & -0.018 & 0.108 & 0.097 \\
SI3 & 0.250 & $\mathbf{0 . 8 4 4}$ & 0.181 & 0.069 & 0.039 \\
AB1 & 0.076 & 0.102 & $\mathbf{0 . 7 0 1}$ & -0.224 & 0.143 \\
AB2 & 0.100 & -0.093 & $\mathbf{0 . 7 0 4}$ & 0.272 & 0.380 \\
AB3 & -0.111 & 0.071 & $\mathbf{0 . 6 0 0}$ & 0.458 & -0.076 \\
AB4 & 0.215 & 0.106 & $\mathbf{0 . 8 6 6}$ & 0.096 & -0.106 \\
SN1 & $\mathbf{0 . 8 3 9}$ & 0.115 & 0.042 & 0.245 & 0.191 \\
SN2 & $\mathbf{0 . 9 1 2}$ & 0.185 & 0.136 & 0.108 & 0.097 \\
SN3 & $\mathbf{0 . 8 7 9}$ & 0.195 & 0.103 & 0.069 & 0.039 \\
PBC1 & 0.294 & 0.336 & 0.072 & -0.148 & $\mathbf{0 . 6 8 9}$ \\
PBC2 & 0.055 & 0.183 & 0.097 & 0.254 & $\mathbf{0 . 8 1 6}$ \\
PS1 & 0.179 & 0.159 & -0.003 & $\mathbf{0 . 7 4 3}$ & 0.238 \\
PS2 & 0.223 & 0.179 & 0.126 & $\mathbf{0 . 8 0 3}$ & -0.026 \\
\hline Eigenvalue & 2.685 & 2.333 & 2.193 & 1.769 & 1.610 \\
Accumulated Contribution of Variance $(\%)$ & 19.178 & 16.663 & 15.666 & 12.638 & 11.498 \\
Contribution of Variance $(\%)$ & 15.666 & 51.507 & 64.145 & 75.643 \\
\hline
\end{tabular}

Then, the model of first-order confirmatory factor analysis (CFA) is constructed to calculate the construct reliability and discriminant validity. The Cronbach's $\alpha$ of the entire scale is $0.849>0.8$, indicating the good internal consistency of the scale. The Goodness-of-Fit Indices of CFA model are demonstrated as follows: RMSEA (the root-mean-square-error of approximation) $=0.023<0.08$, CFI (the comparative fit index) $=0.996>0.9$, GFI (the goodness-of-fit index) $=0.908>0.9$, which indicates the model fits well the collected sample data. As shown in Table 3, the four latent variables' construct reliability values are all higher than 0.6 , meaning the scale has good construct reliability.

Table 3. Results of confirmatory factor analysis.

\begin{tabular}{|c|c|c|c|c|}
\hline Variable & $\begin{array}{l}\text { Factor } \\
\text { Loading }\end{array}$ & $t$-Value & $\begin{array}{l}\text { Construct } \\
\text { Reliability }\end{array}$ & $\begin{array}{l}\text { Variance } \\
\text { Extraction }\end{array}$ \\
\hline Attitude towards the Behavior & - & - & 0.762 & 0.459 \\
\hline $\mathrm{AB} 1$ & 0.532 & - & - & - \\
\hline AB2 & 0.704 & $4.106^{* * *}$ & - & - \\
\hline AB3 & 0.491 & $3.121 * *$ & - & - \\
\hline $\mathrm{AB} 4$ & 0.904 & $4.271^{* * *}$ & - & - \\
\hline Subjective Norm & - & - & 0.914 & 0.781 \\
\hline SN1 & 0.870 & - & - & - \\
\hline SN2 & 0.943 & $10.736^{* * *}$ & - & - \\
\hline SN3 & 0.835 & $8.930 * * *$ & - & - \\
\hline Perceived Behavioral Control & - & - & 0.634 & 0.469 \\
\hline PBC1 & 0.773 & $3.401^{* * *}$ & - & - \\
\hline PBC2 & 0.583 & - & - & - \\
\hline Sharing Intention & - & - & 0.861 & 0.677 \\
\hline SI1 & 0.920 & $7.893^{* * *}$ & - & - \\
\hline SI2 & 0.715 & $6.251^{* * *}$ & - & - \\
\hline SI3 & 0.820 & - & - & - \\
\hline Policy Support & - & - & 0.694 & 0.532 \\
\hline PS1 & 0.744 & $3.239 * *$ & - & - \\
\hline PS2 & 0.714 & - & - & - \\
\hline
\end{tabular}

*** The coefficient significant at $p<0.001$ level; ${ }^{* *}$ the coefficient significant at $p<0.01$ level. 
The convergent validity of each latent variable is shown in Table 4 . The significant level of correlation coefficients indicates that: (1) policy support (PS) is related to the attitude towards behavior $(\mathrm{AB})$ and subjective norm (SN); (2) sharing intention (SI) is related to the attitude of behavior, subjective norm, and perceived behavioral control (PBC). These correlations do not indicate the mutual influence of the variables [25], but justify the theoretical hypothesis (shown in Figure 1) in which specific relationships among series of concerned variables are established.

Table 4. Convergent validity of latent variables.

\begin{tabular}{cccccc}
\hline Latent Variable & AB & SN & PBC & SI & PS \\
\hline AB & 0.459 & - & - & - & - \\
SN & $0.327^{*}$ & 0.781 & - & - & - \\
PBC & 0.234 & $0.402^{*}$ & 0.469 & - & - \\
SI & $0.253^{* *}$ & $0.462^{* *}$ & $0.316^{* *}$ & 0.677 & - \\
PS & $0.267^{* *}$ & $0.471^{* *}$ & 0.215 & $0.471^{* *}$ & 0.532 \\
\hline
\end{tabular}

** The coefficient significant at $p<0.01$ level; * the coefficient significant at $p<0.05$ level.

\section{Model Verification and Hypothesis Test}

\subsection{Model Verification}

The SEM of travelers' EV-sharing acceptance is shown in Figure 2. This paper assesses the goodness-of-fit of the model using chi-square test, the root-mean-square-error of approximation (RMSEA), the comparative fit index (CFI), the goodness-of-fit index (GFI), and the Tacker-Lewis Index (TLI). The indices are computed using AMOS 18.0 (IBM SPSS AMOS: New York, NY, USA; https://www.ibm.com/us-en/marketplace/structural-equation-modeling-sem). The goodness-of-fit indices of the model and the corresponding recommended standards [26,27] are shown in Table 5 . The indices all reach the recommended standards, indicating that the theoretical model fits well the collected sample data.

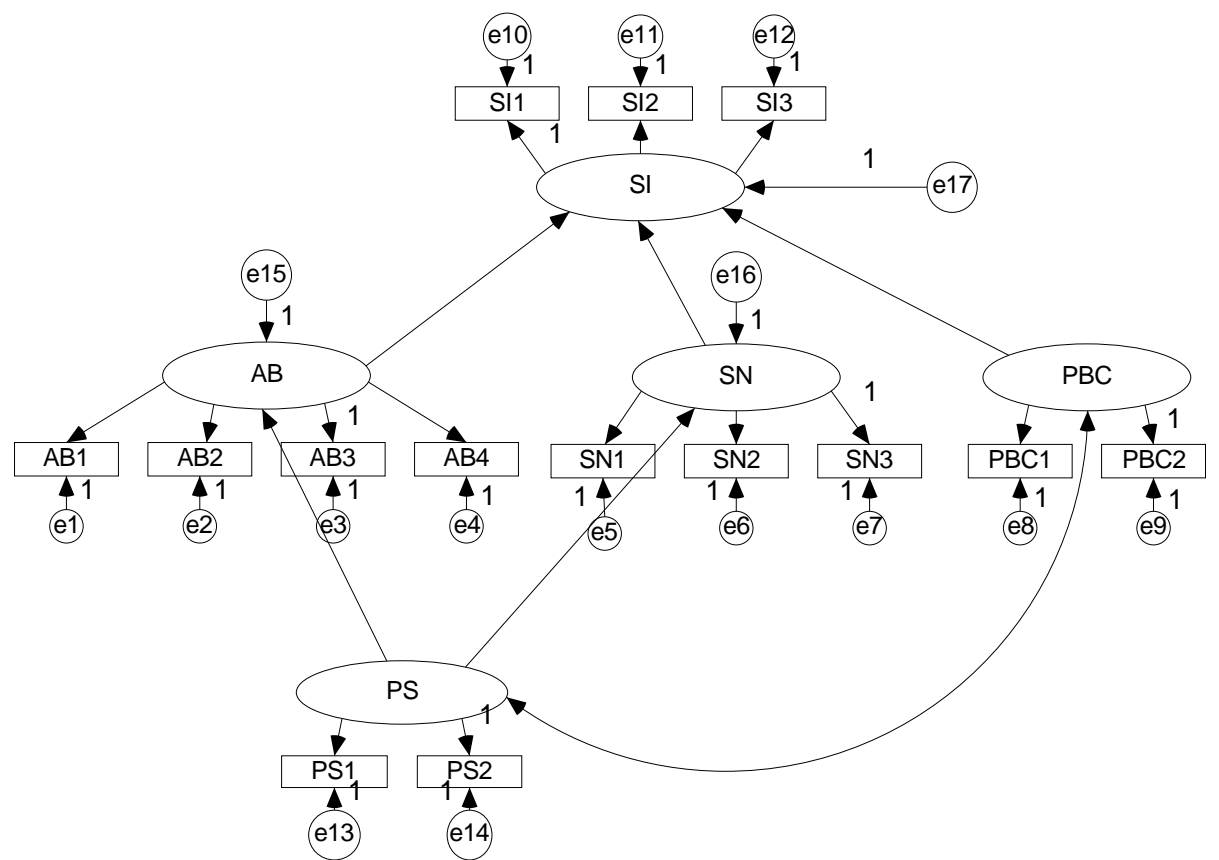

Figure 2. Structural equation model of consumers' EV-sharing acceptance *. * Notes: SI (sharing intention); $\mathrm{AB}$ (attitude towards behavior); $\mathrm{SN}$ (subjective norm); $\mathrm{PBC}$ (perceived behavioral control). 
Table 5. The goodness-of-fit indices of the model and recommended standards.

\begin{tabular}{cccccccc}
\hline & $\chi^{2}$ & $d f$ & $\chi^{2} / d f$ & RMSEA & CFI & GFI & TLI \\
\hline $\begin{array}{c}\text { Recommended } \\
\text { Standard }\end{array}$ & - & - & $\begin{array}{c}1 \sim 3, \text { the hypothetical } \\
\text { model can well fit the } \\
\text { sample data. }\end{array}$ & $\begin{array}{c}<0.05 \text {, good fit; } \\
0.05 \sim 08, \text { reasonable } \\
\text { fit. }\end{array}$ & $>0.9$ & $>0.9$ & $>0.9$ \\
\hline $\begin{array}{c}\text { Experimental } \\
\text { Data }\end{array}$ & 75.748 & 65 & 1.165 & 0.052 & 0.972 & 0.963 & 0.961 \\
\hline
\end{tabular}

\subsection{Path Analysis and Hypothesis Test}

After performing the path analysis, the standardized regression weights among latent variables and their corresponding observed variables can be obtained, as is shown in Table 6 below.

Table 6. Standardized regression weights and its significance level.

\begin{tabular}{ccc}
\hline Path & Standardized Path Coefficient & $\boldsymbol{t}$-Value \\
\hline $\mathrm{AB} \rightarrow \mathrm{SI}$ & 0.069 & 0.571 \\
$\mathrm{SN} \rightarrow \mathrm{SI}$ & 0.347 & $2.630^{*}$ \\
$\mathrm{PBC} \rightarrow \mathrm{SI}$ & 0.530 & $2.823^{*}$ \\
$\mathrm{PS} \rightarrow \mathrm{AB}$ & 0.375 & $2.023^{* *}$ \\
$\mathrm{PS} \rightarrow \mathrm{SN}$ & 0.559 & $3.138^{*}$ \\
$\mathrm{AB} 1 \rightarrow \mathrm{AB}$ & 0.500 & $3.008^{*}$ \\
$\mathrm{AB} 2 \rightarrow \mathrm{AB}$ & 0.711 & $3.799^{* * *}$ \\
$\mathrm{AB} 3 \rightarrow \mathrm{AB}$ & 0.496 & - \\
$\mathrm{AB} 4 \rightarrow \mathrm{AB}$ & 0.919 & $3.841^{* * *}$ \\
$\mathrm{SN} 1 \rightarrow \mathrm{SN}$ & 0.852 & - \\
$\mathrm{SN} 2 \rightarrow \mathrm{SN}$ & 0.955 & $10.2999^{* * *}$ \\
$\mathrm{SN} 3 \rightarrow \mathrm{SN}$ & 0.835 & $8.495^{* * *}$ \\
$\mathrm{PBC} 1 \rightarrow \mathrm{PBC}$ & 0.608 & $3.075^{*}$ \\
$\mathrm{PBC} 2 \rightarrow \mathrm{PBC}$ & 0.665 & - \\
$\mathrm{SI} 1 \rightarrow \mathrm{SI}$ & 0.898 & $7.971^{* * *}$ \\
$\mathrm{SI} 2 \rightarrow \mathrm{SI}$ & 0.716 & $6.202^{* * *}$ \\
$\mathrm{SI} 3 \rightarrow$ SI & 0.836 & - \\
$\mathrm{PS} 1 \rightarrow \mathrm{PS}$ & 0.674 & - \\
$\mathrm{PS} 2 \rightarrow \mathrm{PS}$ & 0.738 &
\end{tabular}

* The coefficient significant at $p<0.01$ level; ** the coefficient significant at $p<0.05$ level; ${ }^{* * *}$ the coefficient significant at $p<0.001$ level.

The results show that the paths among latent variables and their corresponding observed variables

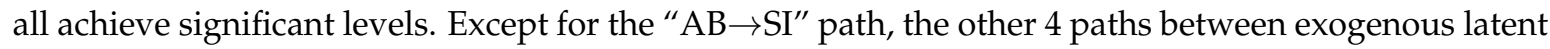
variable and endogenous variable ( $\mathrm{SN} \rightarrow \mathrm{SI}, \mathrm{PBC} \rightarrow \mathrm{SI}, \mathrm{PS} \rightarrow \mathrm{AB}, \mathrm{PS} \rightarrow \mathrm{SN}$ ) all satisfy the requirements of statistically significant levels. Furthermore, the regression weights of these 4 paths are all positive, which is consistent with the hypothesis in the theoretical model in Figure 1. Hence, the results of the verification of the hypotheses are given as shown in Table 7.

Table 7. Verification of the hypotheses.

\begin{tabular}{ccc}
\hline Path & Direction & Result \\
\hline Hypothesis 1: $\mathrm{AB} \rightarrow$ SI & + & Not supported \\
Hypothesis 2: $\mathrm{SN} \rightarrow$ SI & + & Supported \\
Hypothesis 3: PBC $\rightarrow$ SI & + & Supported \\
Hypothesis 4: PS $\rightarrow$ AB & + & Supported \\
Hypothesis 5: PS $\rightarrow$ SN & + & Supported \\
\hline
\end{tabular}

The total effects among exogenous latent variables and endogenous variables are shown in Table 8 . The greater coefficient value indicates that the independent variables have a greater impact on 
their corresponding dependent variables. Hence, the coefficients provide a quantitative criterion of calculating the devotions of different contributors. The devotions of independent variables to sharing intention are ranked by importance as follows: perceived behavioral control (0.530), subjective norm (0.347), policy support (0.219), and the attitude towards behavior (0.069). The mediating effect of policy support on the attitude toward behavior and subjective norm are 0.375 and 0.559 , respectively.

Table 8. Standardized total effects among latent variables.

\begin{tabular}{ccccc}
\hline & AB & SN & PBC & PS \\
\hline AB & - & - & - & 0.375 \\
SN & - & - & - & 0.559 \\
SI & 0.069 & 0.347 & 0.530 & $0.219^{*}$ \\
\hline
\end{tabular}

Notes: exogenous variables and endogenous variables are arranged in row and column, respectively; * the value here characterizes standardized indirect effect.

\section{Discussion}

\subsection{Research Findings}

\subsubsection{The Acceptance of EV Sharing Varies on Different Demographic Features}

Table 9 demonstrates the mean comparison among different people on the EV-sharing-related knowledge and sharing intention. As shown in Table 2, in comparison with females, males acquire significantly more EV-sharing-related knowledge, but are significantly less interested in EV sharing. People who do not own household vehicles have significantly less EV-sharing knowledge compared to people who own at least one private car, but there are no significant differences existing in sharing intention between them. Likewise, although people who travel by public transit have more interest in EV sharing than those who travel by private car, the result fails to achieve a significant level.

Table 9. The mean comparison on sharing knowledge and intention.

\begin{tabular}{|c|c|c|c|c|c|c|c|}
\hline \multirow{2}{*}{\multicolumn{2}{|c|}{ Variables }} & \multicolumn{3}{|c|}{ Familiar to the EV-Sharing Knowledge } & \multicolumn{3}{|c|}{ Intention to Participate in EV Sharing } \\
\hline & & Mean & SD & $t$-Test & Mean & SD & $t$-Test \\
\hline \multirow{2}{*}{ Gender } & male & 3.21 & 1.18 & \multirow{2}{*}{$\begin{array}{c}t(60)=1.966 \\
p=0.008\end{array}$} & 3.33 & 0.64 & \multirow{2}{*}{$\begin{array}{c}t(60)=-0.454 \\
p=0.014\end{array}$} \\
\hline & female & 2.84 & 1.21 & & 3.42 & 0.66 & \\
\hline \multirow{2}{*}{$\begin{array}{l}\text { Vehicle } \\
\text { number }\end{array}$} & none & 3.43 & 0.7 & \multirow{2}{*}{$\begin{array}{c}t(60)=-1.345 \\
p=0.039\end{array}$} & 3.27 & 0.48 & \multirow{2}{*}{$\begin{array}{c}t(60)=-0.807 \\
p=0.542\end{array}$} \\
\hline & at least 1 & 3.51 & 0.42 & & 3.42 & 0.51 & \\
\hline \multirow{2}{*}{$\begin{array}{l}\text { Travel } \\
\text { mode }\end{array}$} & public transit & 3.05 & 0.52 & \multirow{2}{*}{$\begin{array}{c}t(60)=0.045 \\
p=0.977\end{array}$} & 3.45 & 0.57 & \multirow{2}{*}{$\begin{array}{c}t(60)=-0961 \\
p=0.354\end{array}$} \\
\hline & private car & 3.04 & 0.56 & & 3.27 & 0.39 & \\
\hline
\end{tabular}

\subsubsection{The Attitude towards Behavior Insignificantly Influences Sharing Intention}

It is found that consumers' attitude does not affect them choosing EV sharing, which is consistent with previous research findings in this field. A meta-analysis on psychological correlations of car use highlights a general lack of evidence of effects of proenvironmental cognitions on behavior or intentions [28]. A study on green consumer market segmentation in Portugal showed that Portuguese consumers, despite their support for the policies designed to improve the environment, do not always translate their concerns into environmentally friendly actions [29]. Similarly, a study on environmental attitudes and behavior of consumers in China concluded that Chinese consumers demonstrate a powerful environmental effect, but their actions in protecting the environment are still insignificant [30]. The reason for the insignificant relationship between attitude and sharing intention can be explained as follows. EV sharing has a significant external character, which means that consumers have to pay extra money for environment conservation while receiving little feedback. Moreover, EV's market immaturity in vehicle performance compared to ICEVs and the limitations of supporting infrastructure 
intensify the externality of EV sharing. All negative factors act together to cause the uncertainty in the relationship between attitude and EV-sharing intention, characterized by the low path weight and its insignificance. The obscure relationship implies that even positive-attitude holders might not participate in EV sharing in reality.

\subsubsection{Subjective Norm and Perceived Behavior Control Both Have Significant Positive Effects on} Sharing Intention

The attitude shaped by consumers themselves is feeble in transforming into actual activity. However, the social pressures, expressed by the recommendation from family members or friends, can significantly affect sharing intention. Promoting EV sharing requires external encouragements over than inner perceptions. Consumers with strong perceived behavioral control are more likely to participate in EV sharing even with the knowledge of the limitation of EVs' performance and their supporting infrastructures.

\subsubsection{Policy Support Affects Sharing Intention via Mediating Effect}

Policies to restrict the use of ICEVs and increase emission standards can indirectly change the intention of EV sharing. However, policy support affects EV-sharing intention mostly through other people's opinion, rather than perceptions from consumers themselves. Considering the relatively small contribution made by the attitude towards behavior to sharing intention, the indirect effect of policy support on sharing intention is measured mainly by the mediated variable subjective norm, as shown in Equation (4). The route devotion made by mediated variable subjective norm is shown in Equation (5).

$$
\begin{aligned}
& \text { Indirect } E f f e c t_{P S \rightarrow S N \rightarrow S I}=\text { Direct }_{E f f e c t} \text { PS } \rightarrow S N_{N} * \text { Direct } \text { ffect }_{S N \rightarrow S I} \\
& =0.559 * 0.347=0.194 \\
& \text { Route Devotion }_{P S \rightarrow S N \rightarrow S I}=\frac{\text { Indirect }_{\text {Effect }} P S \rightarrow S N \rightarrow S I}{\text { Total }_{\text {Effect }} \rightarrow S \rightarrow S I} \\
& =\frac{0.194}{0.219}=88.58 \%
\end{aligned}
$$

The result of Equation (5) reveals the theoretical mechanism that policy support has an influence on sharing intention. The policy support can widely affect the preference of EV sharing. However, the consumers' sharing intention is mostly affected by the evaluations from family members or friends, rather than the perceptions by themselves. In other words, the consumers' inner perceptions of EV sharing act weakly in determining their sharing behavior. They need to search for confirmations from people who are important to themselves, usually family members or friends. Their support for participating in EV sharing will significantly increase the possibility of travelers' EV-sharing behavior.

\subsection{Recommedations to Promote EV Sharing}

5.2.1. Providing More Accessible Resources of EV Sharing, Highlights on Improving the Perceived Behavioral Control

As the perceived behavioral control has the greatest significant impact on sharing intention ( $\xi=0.530, p=0.01$ ), enhancing the PBC should enjoy the priority when it comes to adding sharing intention. Based on the $\mathrm{PBC}$ 's definition, the more opportunities or resources that a person has access to, the more likely he will feel at ease to perform the particular behavior. Hence, constructing more charging piles on road networks or equipping more sharing vehicles at each service station will make the travelers regard EV sharing and EV purchasing as a convenient and reliable travel mode. As the accessible resources increase, the consumers' perceived behavioral control improves as well, which results in the adding of sharing intention. 


\subsubsection{Improving Social Pressure, Keeping Focus on Enhancing Subjective Norm}

Enhancing the travelers' subjective norm is an important means to promote EV sharing as the significant path coefficient exists between subjective norm and sharing intention $(\eta=0.347, p<0.01)$. According to the definition of subjective norm, an individual's perception about a particular behavior is influenced by the judgment of significant others or, say, social pressure. By offering free use or discounts, some travelers will take part in EV sharing and form the start nodes. Their sharing behaviors will imperceptibly persuade other people who are close to them to participate in sharing too, which could be characterized as silent social pressure. As more people take part in sharing, the subjective norm accumulates with the increasing social pressure, leading to more sharing participants.

\subsubsection{Under Current Condition, Propaganda Aiming to Promote Behavioral Attitude Is Not an Effective Way}

The attitude toward behavior is unable to effectively increase sharing intention as the path coefficient is not significant $(\eta=0.069, p>0.05)$. Based on the definition, the behavioral attitude is related to the evaluation of behavioral outcomes. Recently, propaganda of promoting EV sharing has been divided into two categories, one to promote a green travel mode, the other to demonstrate the cost-saving effect compared to traveling by private petrol car. No matter which type the propaganda belongs to, the essential is to increase travelers' positive evaluations before actually participating in EV sharing, further improving the attitude towards behavior. However, within current technology, facility, and policy conditions, propaganda tends to be in vain as the correlation between the attitude towards behavior and sharing intention doesn't reach the significant level.

\subsubsection{Policy Works Better When It Focuses on Improving Social Pressure}

Policy support has two means to affect sharing intention, via the mediated variable attitude towards behavior (indirect effect 0.026) or via the mediated variable subjective norm (indirect effect 0.194). Hence, one could draw the conclusion that policy focus on improving social pressure might work in a more effective way. For instance, launching laws to guarantee a certain number of charging piles in new residential areas, or implementing regulations that EV is free from in rush hour of workdays will promote the development of EV sharing. As the number of people trying this new type of travel mode is increasing, social pressure accumulates as well, which results in including more people in the sharing activity.

\section{Conclusions}

The SEM of EV-sharing acceptance is established and justified to illustrate the influential mechanism of the attitude towards behavior, subjective norm, perceived behavioral control, and policy support on sharing acceptance. This study confirms the determinant roles of both subjective norm and perceived behavioral control in promoting sharing intention and simultaneously proves the mediating effect of policy support. From the results, the importance of policy support is revealed. Launching laws to improve the development of EV application can be an efficient way, for example, enhancing the convenience of charging stations, or financial subsidy for EV purchase and utilization (including EV sharing). According to the result of improving social pressure, EV sharing is easily spread in a sustainable atmosphere. Therefore, promoting energy conservation and environmental protection are also important. There is no gainsaying the fact that the EV still has shortcomings, which affect the popularization of EVs. The development of EV sharing needs more policy support.

The limitations of this study are interpreted as follows. First, as EV sharing is a totally new innovative travel mode in Beijing, the lack of personal experiences causes the fluctuation of questionnaire answers. As a result, we have to eliminate some irrelevant items. This leads to the fact that we have two latent variables assessed with only two items, which might undermine the power to capture the multidimensional nature of the latent variable. Second, this study merely draws an 
illustration of how the SEM of EV-sharing acceptance works. For example, the study constructs the SEM through taking the whole questionnaire samples into consideration. Hence, future studies should be warranted to include more demographic information, such as gender, age, income, daily travel mode, and number of household vehicles, in the SEM to process the simultaneous analysis of several groups. An elaborate division of sample groups helps to provide a more effective solution to promote EV sharing targeting specific travelers sharing the same demographic characters. Third, apart from behavioral intention, the individual behavior is affected by opportunities and resources around them. Considering the quick development of EV technology and the construction of charging piles in large scale, the traveler's perspective of EV sharing might have changed with time. Hence, the model should acquire the latest stated preference survey data so as to give an accurate interpretation of travelers' sharing behavior.

Author Contributions: Conceptualization, K.Z.; methodology, Y.Z., H.G; data analysis, G.Y.; writing—original draft preparation, H.G., Y.Z.; writing—review and editing, H.G., C.L.; supervision, H.G., W.W.

Funding: This research was supported in part by the National Nature Science Foundation of China under grant 51878045, 71871130, 71734004 .

Conflicts of Interest: The authors declare no conflict of interest.

\section{References}

1. Baum, H.; Pesch, S. Untersuchung der Eignung von CarSharing im Hinblick auf Reduzierung von Stadtverkehrsproblemen; Research report No. 70421/93; German Ministry of Transport: Köln, Germany, 1994.

2. Katzev, R. Car Sharing: A New Approach to Urban Transportation Problems. Anal. Soc. Issues Public Policy 2003, 3, 65-86. [CrossRef]

3. Lightfoot, G. Pay as You Drive Carsharing; Final Report XVII/4.1031/95-025; Community Research and Development Information Service, European Commission: Brussels, Belgium, 1997.

4. Shaheen, S.A.; Cohen, A.P. Carsharing and personal vehicle services: Worldwide market developments and emerging trends. Int. J. Sustain. Transport. 2013, 7, 5-34. [CrossRef]

5. Cruz, N.F.D.; Marques, R.C. Scorecards for sustainable local governments. Cities 2014, 39, 165-170. [CrossRef]

6. Kley, F.; Lerch, C.; Dallinger, D. New business models for electric cars: A holistic approach. Energy Policy 2011, 39, 3392-3403. [CrossRef]

7. Dijk, M.; Orsato, R.J.; Kemp, R. The emergence of an electric mobility trajectory. Energy Policy 2013, 52, 135-145. [CrossRef]

8. Shaheen S., A.; Cohen, A.P. Shared ride services in North America: definitions, impacts, and the future of pooling. Trans. Rev. 2018. Available online: https://www.tandfonline.com/doi/abs/10.1080/01441647.2018. 1497728 (accessed on 3 December 2018). [CrossRef]

9. Hildermeier, J.; Villareal, A. Two ways of defining sustainable mobility: Autolib' and BeMobility. J. Environ. Policy Plann. 2014, 16, 321-336. [CrossRef]

10. Barth, M.; Todd, M. User Behavior Evaluation of an Intelligent Shared Electric Vehicle System. Transport. Res. Rec. 2001, 1760, 145-152. [CrossRef]

11. Kim, D.; Ko, J.; Park, Y. Factors affecting electric vehicle sharing program participants' attitudes about car ownership and program participation. Transp. Res. Part D 2015, 36, 96-106. [CrossRef]

12. Simões, P.; Marques, R.C. On the economic performance of the waste sector. A literature review. J. Environ. Manag. 2012, 106, 40-47. [CrossRef]

13. Wu, Y.; Wang, R.J.; Zhou, Y.; Lin, B.; Fu, L.; He, K.; Hao, J. On-road Vehicle Emission Control in Beijing: Past, Present, and Future. Env. Sci. Tech. 2011, 45, 147-153. [CrossRef] [PubMed]

14. Lois, D.; Lopez-Saez, M. The relationship between instrumental, symbolic and affective factors as predictors of car use: A structural equation modeling approach. Transp. Res. Part A 2009, 43, 790-799. [CrossRef]

15. Ajzen, I. The theory of planned behavior. Organ. Behav. Hum. Decis. Process 1991, 50, 179-211. [CrossRef]

16. Hidrue, M.K.; Parsons, G.R.; Kempton, W.; Gardner, M.P. Willingness to pay for electric vehicles and their attributes. Resour. Energ. Econ. 2011, 33, 686-705. [CrossRef] 
17. Miao, R.; Cao, J.T.; Zhang, K.; Chen, B.X.; Jiang, Z.B.; Wang, L.Y. Value-added path of service-oriented manufacturing based on structural equation model: The case of electric car rental for instance. Int. J. Prod. Res. 2014, 52, 5502-5513. [CrossRef]

18. Ajzen, I.; Fishbein, M. Understanding Attitudes and Predicting Social Behavior; Prentice-Hall: Englewood Cliffs, NJ, USA, 1980.

19. Warner, H.W.; Aberg, L. Drivers' beliefs about exceeding the speed limits. Transp. Res. Part F 2008, 11, 376-389. [CrossRef]

20. Rozario, M.; Lewis, I.; White, K.M. An examination of the factors that influence drivers' willingness to use hand-held mobile phones. Transp. Res. Part F 2010, 13, 365-376. [CrossRef]

21. Ajzen, I. From Intentions to Actions: A Theory of Planned Behavior. In Action Control: From Cognition to Behavior; Kuhl, J., Beckmann, J., Eds.; Springer-Verlag: Berlin, Germany, 1985; pp. 11-39.

22. Armitage, C.J.; Conner, M. Efficacy of the theory of planned behavior: A meta-analytic review. Br. J. Soc. Psychol. 2001, 40, 471-499. [CrossRef]

23. Ajzen, I. Nature and operation of attitudes. Annu. Rev. Psychol. 2001, 52, 27-58. [CrossRef]

24. Ajzen, I. Perceived behavioral control, self-efficacy, locus of control, and the theory of planned behavior. J. Appl. Soc. Psychol. 2002, 32, 665-683. [CrossRef]

25. Carmines, E.G.; Mciver, J.R. Analyzing Models with Unobservable Variables. In Social Measurement Current Issues; Bohrnstedt, G.W., Borgatta, E.E., Eds.; Sage: New York, NY, USA, 1981; pp. 65-115.

26. Bentler, P.M.; Dudgeon, P. Covariance structure analysis: Statistical practice, theory, and directions. Annu. Rev. Psychol. 1996, 47, 563-592. [CrossRef] [PubMed]

27. Browne, M.W.; Cudeck, R. Alternative Ways of Assessing Model Fit. In Testing Structural Equation Models; Bollen, K.A., Long, J.S., Eds.; Sage: New York, NY, USA, 1993; pp. 136-162.

28. Gardner, B.; Abraham, C. Psychological correlates of car use: A meta-analysis. Transp. Res. Part F 2008, 11, 300-311. [CrossRef]

29. Paco, A.M.F.; Raposo, M.L.B. Green consumer market segmentation: Empirical findings from Portugal. Int. J. Consum. Stud. 2010, 34, 429-436. [CrossRef]

30. Chan, R. Environmental attitudes and behavior of consumers in China: Survey findings and implications. J. Int. Consum. Mark. 1999, 11, 25-52. [CrossRef] 